\title{
o catecumenato no evangelho de marcos *
}

\author{
The Catechumenate in the Gospel of Mark
}

José Carlos Silva Carvalho **

RESUMO: Neste artigo, pretende-se mostrar como o discipulado no evangelho de Marcos surge antes de qualquer ritualidade, o que nos faz regressar aos praenotanda do R.I.C.A. (Ritual de Iniciação Cristã de Adultos) e aos processos catecumenais. Sem apresentar a expressão, Marcos narra o percurso dos discípulos como um procedimento catecumenal, em que o grande catequista é Jesus. Para tal, partindo das personagens deuteragonistas - os discípulos - é possível verificar qual a parte do processo batismal que é relevada pelo evangelista, pois é de um processo que se trata. Os discípulos são envolvidos num catecumenato pelo grande catequista Jesus, percurso que atravessa todo o segundo evangelho canônico. Isso faz do discipulado em Marcos um catecumenato, que da parte de Jesus consiste num processo de familiarização.

PALAVRAS-CHAVE: Catecumenato. Discípulos. Batismo. Processo. Rito.

ABSTRACT: This article aims to show how the discipleship in the gospel of Mark arises before any rituality, which leads us to return to the previous and very important notes of the Christian Adults Initiation Ritual and to the catechumenal processes. Mark, without using the expression, narrates the disciples' journey as a catechumenate procedure in which Jesus is the master catechist. To this end, starting from the deuteragonist characters, i.e., the disciples, it is possible to verify which part of the baptismal process is revealed by the evangelist, because it is a process that is at stake. The disciples are involved in a catechumenate by the master catechist, Jesus. This is a journey that goes through the entire second canonical gospel. This makes the discipleship in Mark a catechumenate, which, from the part of Jesus is a procedure of familiarization.

KEYWORDS: Catechumenate. Disciples. Baptism. Procedures. Ritual.

\footnotetext{
* Este texto é uma reelaboração da comunicação apresentada a 03-02-2020 nas Jornadas de Teologia sobre A Iniciação Cristã em tempos de secularização que tiveram lugar na Universidade Católica Portuguesa (UCP) no Porto.

** Universidade Católica Portuguesa, Porto, Portugal.
} 


\section{Introdução}

Ta construção do evangelho de Marcos, o evangelista não centrou a 1 sua atenção apenas na personagem principal - Jesus. Distribuiu várias personagens secundárias (deuteragonistas) e terciárias (tritagonistas) ao longo do texto e, sobretudo na segunda parte do evangelho (a partir de Mc 8,27), centra a sua atenção no grupo dos discípulos. Essa construção narrativa pretende chamar a atenção do leitor ouvinte, o que é conseguido também com a intervenção de outras personagens menos importantes que os discípulos, as personagens terciárias. Com esses dois grupos, o evangelista vai indicando qual é o lugar e a vocação do discípulo. Neste artigo pretendemos mostrar como tal não é apenas comparável a um processo de catecumenato, mas é um catecumenato, com todas as exigências, circunstâncias, intervenientes, objetivos e processos que o constituem.

\section{0 catecumenato como familiarização no evangelho de Marcos}

O verbo baptízō traduz os verbos hebraicos thābal (mergulhar), bō' (ir), tzəbaCE (embeber) e maHaz (lavar) na versão dos Setenta (HATCH; REDPATH, 1998, p. 190). Mas esse campo lexical não é usado por Marcos para traduzir a experiência discipular e o inerente processo de familiarização progressiva que ela comporta. É, por isso, sintomático que Jesus não batize ninguém no evangelho de Marcos e que também não encontremos no segundo evangelho canônico a etimologia da catequese e do catecumenato do verbo katēkhéō (que significa segurar, reter, captar, agarrar, ter segundo o que, soar ao lado de, ensinar, informar: cf. Lc 1,2-4) ou do substantivo katēkhoúmenos (catecúmeno). Jesus deixa-se batizar por João, mas Jesus não batiza ninguém. A única ocasião no evangelho de Marcos em que Jesus utiliza o verbo baptízō é em Mc 10,38 quando está a acabar a subida para Jerusalém, anunciando então aos filhos de Zebedeu que serão batizados no batismo em que Ele vai ser batizado na Paixão: Jesus está aí a anunciarlhes o mergulho na morte, a entrega da vida pelo mundo e pelos seus, pelo que o verbo não assume o sentido ritual com que hoje o conotamos. Excetuamos aqui a segunda conclusão do evangelho (Mc 16,9-20) por ser posterior. Os dois filhos de Zebedeu nem querem um batismo de desejo e muito menos um batismo de sangue, porque não entendem a etimologia do verbo: ser lavado/mergulhado na morte.

Ainda que o rito do batismo não seja tema no segundo evangelho canônico, o que precede esse rito é: todo o caminho e o processo de catecumenato com o qual Jesus vai construindo uma relação familiar com os seus discípulos. Jesus em Marcos é um grande catequista e a comunidade dos 
discípulos é o conjunto dos catequizandos e catequizandas. O grande catequista Jesus insere os seus catequizandos na sua vida. Podemos dizer que Jesus vai, ao longo do evangelho de Marcos, iniciando à vida cristã da fé aqueles discípulos mais adultos. Jesus perpassa alguns momentos e algumas das possibilidades dos praenotanda do R.I.C.A. (Ritual da Iniciação Cristã de Adultos). São esses momentos que aqui apresentamos, pois são eles que fazem com que estejamos diante do evangelho do discipulado e dos catecúmenos. Essa condição discipular catecumenal faz parte das preocupações pastorais do Papa (FRANCISCO, 2013, n. 217-237), que alerta que a dinâmica própria da fé consiste sobretudo em iniciar processos, pois os tempos são maiores do que os espaços, a totalidade é maior do que as partes, a realidade é mais do que a ideia e a unidade supera o conflito. Desse ponto de vista, o catecumenato marcano assume uma evidente importância de atualização pastoral. Essa atualidade chega pela própria disposição narrativa e pela respectiva construção ao longo do texto do evangelho. Importa de ela isolar alguns momentos, apenas, para vermos a mecânica narrativa a construir nos discípulos a identidade de Jesus, e a construir no narratário a comunidade dos discípulos à maneira de uma família.

\section{As figuras narrativas}

Nas últimas décadas, a exegese do evangelho de Mc tem abdicado do modo tradicional de estudar os títulos cristológicos isoladamente e tem privilegiado o método narrativo, inserindo estes títulos - messias, Filho de Deus, Cristo - no contexto narrativo da macro-estrutura do texto evangélico, ou seja, lidos intradiegeticamente ao nível da diegese interna e externa do evangelho quando analisamos qualquer perícope (MASCILONGO, 2011, p. 334). No fundo, tem investigado o alcance narrativo dos títulos, o que significam para o leitor e para o narrador do evangelho de Mc. Essa aproximação narratológica à cristologia do evangelho, ou seja, à imagem que é dada de Jesus a partir dos títulos ao longo da narrativa, constrói uma cristologia narrativa. De fato, "a narratologia faz sentido" (VAN OYEN, 2019, p. 6, tradução nossa). Esses títulos só são compreensíveis se, metodologicamente, for tida em conta a evolução narrativa. Aqui, assumem lugar de primordial relevo o momento de reconhecimento (anagnốrisis) de Pedro em Mc 8,27-30, o papel das personagens menores deuteragonistas ou tritagonistas, ditas também "funcionais" (ALETTI, 2005, p. 23) ou "menores" (BOURQUIN, 2019, p. 73, tradução nossa), e as injunções ao longo do evangelho, quer aos discípulos, quer aos miraculados por Jesus, o protagonista principal, a "figura principal" (BREYTENBACH, 2019, p. 95, tradução nossa). As injunções acontecerão ao longo da subida para Jerusalém (Mc 8,27-10,52), e a bios que é o evangelho de Marcos desemboca 
neste outro momento anagnorístico do centurião aos pés da cruz, quando exclama em Mc 15,39: "verdadeiramente, este homem era filho de Deus", formando assim uma grande inclusão com Mc 1,1. Narratologicamente, isso marca um processo narrativo, mas não apenas, pois na respetiva narratividade Marcos constrói para os discípulos a identidade de Jesus, e nessa construção também arquiteta uma relação familiar. Essa relação pressupõe uma familiaridade, a qual é detectada pelos leitores intra e extradiegéticos (pela diegese interna e externa) como um processo de familiarização inerente a um processo de catecumenato, pois Jesus quer levar os discípulos até ao batismo da cruz ao longo desse catecumenato, e sempre junto a si. Aquele epifonema na boca do centurião (um não discípulo) é, por isso, um marco na construção narrativa da identidade de Jesus e, por ser um marco narrativo anagnorístico, é um momento catecumenal. Narrativamente, é a "última declaração" (ALETTI, 2005, p. 35 , tradução nossa) $)^{1}$ de que Jesus é o Filho de Deus. Ainda que não seja só aí $^{2}$, na personagem tritagonista do centurião encontram-se os leitores intradiegéticos e extradiegéticos. Aquele tritagonista lê e é lido, narra e é narrado para o narratário. Essa personagem, que nem secundária é, remete para a personagem principal e para as personagens deuteragonistas (os discípulos) que tinham começado o catecumenato lá na Galileia. Assim, um não catecúmeno lê os catecúmenos que abandonaram Jesus em sexta-feira santa e lê o próprio Jesus. O centurião, ao usar o imperfeito do verbo (era) para identificar Jesus como filho de Deus, mostra pela pena de Marcos que reconhece essa filiação já desde os inícios do catecumenato nos inícios do ministério público na Galileia. Esse imperfeito ên

mostra que a confissão é uma avaliação do passado. Jesus era Filho de Deus ao longo de um ministério que começou quando Deus afirmou aquela verdade (Mc 1:11), mesmo que até então nenhum ser humano a tenha reconhecido (BROWN, 1994, p. 1151, tradução nossa).

Mas, a este tritagonista, Jesus não pode impor nem injunções nem silêncios. Ora, Marcos sabe isso e explora isso. Narrativamente, existe aqui toda uma construção literária (narratológica) e (por essa via) teológica que explora as incidências e os silêncios das personagens deuteragonistas e tritagonistas ao longo do processo catecumental que vai desde a Galileia até Jerusalém, até chegar ao momento anagnorístico desse tritagonista não catecúmeno, mas que recolhe o sentido das injunções até aí. Por recolher até aí essas injunções, Marcos dá um lugar central à confissão de Pedro

\footnotetext{
${ }^{1}$ Consideramos que o debate exegético continua a oscilar entre a anagnorese do centurião em perfeita sintonia inclusiva com o título do evangelho em 1,1 ("Filho de Deus") e a récognition do neaniskos (jovem) na manhã da ressurreição (BOURQUIN, 2010, p. 34), na medida em que o mise en abyme prolonga-se até à ressurreição, onde quer Marcos fazer chegar o leitor ouvinte. ${ }^{2}$ Com efeito, Gnilka (1986, p. 400) prolonga esse processo de anagnorese até ao jovem vestido de branco sentado no sepulcro (Mc 16,5), sendo esse o momento que "constitui o ponto culminante do evangelho" (tradução nossa).
} 
em Cesareia de Filipe, bem lá no norte, longe de Jerusalém tanto espiritual como teologicamente. Estrategicamente colocada no meio do evangelho, a dita confissão de Pedro recapitula todos os sinais da primeira parte do evangelho, ao longo do qual os discípulos vão encontrando as marcas de Jesus, as quais têm de descodificar. Essa tarefa hermenêutica é apresentada quer na óptica dos catecúmenos internos, quer dos externos ao texto, sabendo que os catecúmenos externos ao texto (o leitor ou o narratário) por vezes têm mais informação do que os que são internos à narrativa, como é normal acontecer numa narrativa em que o discourse olha a story (ALETTI, 2007, p. 84). Assim, a confissão de Pedro assume uma função recapitulativa, é uma "analepse interna" de vários episódios do catecumenato da primeira parte, entre os quais, o episódio da reação de Herodes de Mc 6,14-16 depois da morte de João Batista (MASCILONGO, 2011, p. 74). A partir de Cesareia de Filipe, o estilo do catecumenato intensifica-se, pois vão surgir várias injunções ao silêncio. Por que motivo?

Com efeito, as injunções ao silêncio adquirem uma progressão narrativa cuja sequência vai mostrando os seus efeitos. Elas apresentam uma função cristológica não tanto corretiva, mas de "reformulação do conceito messiânico" (CARVALHO, 1998, p. 235) que emerge progressivamente ao longo da narrativa evangélica, até desaparecer depois da transfiguração em Mc 9,7-9 (a partir de onde desaparecem os verbos diastéllomai e diēgéomai). Se Jesus manda calar os deuteragonistas (personagens secundárias) e os tritagonistas (personagens terciárias), isso tem uma evidente função narrativa, logo, cristológica. A identidade cristológica de Jesus é construída com os títulos que essas personagens deuteragonistas e tritagonistas dizem, ou pelas injunções ao silêncio a que Jesus submete-as até à Páscoa. Seja como for, esses silêncios impostos por Jesus também compõem o catecumenato, ou seja, fazem parte do catecumenato marcano de Jesus injunções e silenciamentos, mas não só. Existe uma evidente pedagogia para os leitores intra e extradiegéticos: existe uma progressividade no conhecimento de Jesus, tal como acontece num processo de catecumenato. Isso supõe uma empatia progressiva, um processo de familiarização a Jesus, como é próprio dos catecúmenos.

Tornou-se famosa a tese de Wrede, segundo a qual essas injunções não remontariam ao próprio Jesus histórico, mas teriam sido criadas e inseridas pela posterior e primeira comunidade cristã (FOCANT, 2006, p. 55.72) que teria redigido o evangelho para superar o aparente fracasso de Jesus, a ausência de uma anagnorese no fim do evangelho de Mc, na medida em que é no mínimo estranho que a boa notícia do evangelho termine na primeira conclusão em Mc 16,8 com um efoboûnto gár ("temiam, com efeito"). A primitiva comunidade teria posto na boca de Jesus a ordem para silenciar a sua identidade, para preparar o leitor para a deserção final dos discípulos e para aquele fim em Mc 16,1-8: o segredo messiânico resolveria estas aporias (GONZÁLEZ RUIZ, 1988, p. 40-41). Essa leitura de Wrede teve 
sucesso durante várias décadas ao longo do último século, mas foi perdendo força no final do século passado, visto que os exegetas consideravam ser esse um falso problema (ALETTI, 2015, p. 22). No entanto, a mesma exegese também distingue um receio positivo e um receio negativo, como mostrou Camille Focant. Com efeito, o uso do verbo thambesthai (recear) na primeira parte do evangelho tem o objetivo positivo de evidenciar, pela reação receosa dos conterrâneos de Jesus, os milagres e o poder do Filho de Deus (cf. Mc 4,40-51; 5,31; 6,37; 8,4); mas também permite a Marcos traduzir (num sentido negativo) a reprovação de que são alvo $(4,13 ; 6,50-$ 52; 7,18; 8,16-21) por parte de Jesus (FOCANT, 2006, p. 72).

Nessa aproximação narratológica ao evangelho haverá, entre outras questões, que perguntar qual é a função da declaração divina da transfiguração em Mc 9,2-9 e da primeira conclusão de Mc 16,8: a função de Mc 9,2-9 parece ser a mesma de Mc 1,1, ou seja, confirmar diante dos discípulos as afirmações de Jesus a propósito da sua rejeição e dos seus sofrimentos (ALETTI, 2015, p. 24). Consideramos, contudo, que é necessário alargar esta pesquisa, pois o papel das personagens tritagonistas, podendo não ser submetidas a qualquer injunção a partir do episódio da Transfiguração, falam de outro modo (como é o caso do cego Bartimeu no fim da subida para Jerusalém).

Sendo assim, a exegese vê-se obrigada a considerar narrativamente o que vai acontecendo ao longo da trama do evangelho, da intriga da narrativa. Isso obriga a olhar para o que diz o narrador, para o que diz Jesus de si mesmo, para o que dizem os discípulos e as personagens menores, ou seja, obriga a averiguar qual é a cristologia dos interlocutores de Jesus (deutero e tritagonistas), seja pelos silêncios impostos ou declarados, pois neles são espelhados os leitores intra e extradiegéticos. Não nos concentraremos no comentário dos episódios anagnorísticos da confissão de Pedro em Cesareia de Filipe (Mc 8,27-30)3 , ou da Transfiguração (Mc 9,2-9), nem do centurião, mas importa fazer uma avaliação do conjunto de forma comparativa que, sobretudo, se foque nos níveis de leitura, tendo em conta que o leitor se pode identificar com o narratário extra-diegético presente em todas as perícopes e, desse modo, pode recordar e confrontar-se com todas essas personagens. O leitor também é desafiado à familiarização a Jesus nesse processo catecumenal. Para tal, Marcos apresenta na primeira parte vários casos que obrigam primeiro a uma diegese interna para que o leitor extradiegético vá identificando quem é o Cristo que dá título ao evangelho. Esse é, no fundo, um catecumenato que começa por ser narrativo, interno ao texto evangélico, para se tornar externo a ele. A esse nível, o leitor encontra na primeira parte do evangelho vários confrontos, quer com os discípulos catecúmenos, quer com Jesus: o episódio com os demônios (Mc 3,7-12.20-35), em Nazaré (6,1-6a), a cura em 7,31-37, a surpresa perante o

\footnotetext{
3 "Marcos [...] faz deste conjunto um elemento charneira mesmo no centro do evangelho" (LÉGASSE, 1997, p. 498, tradução nossa).
} 
poder de Jesus (1,21-28) e as disputas iniciais no ministério de Jesus (2,1$3,5)$. Ao longo desses episódios, o leitor ouvinte vai fazendo um percurso de identificação progressiva da identidade de Jesus e é "chamado a um caminho de aproximação da história narrada, a não desprezar as vantagens, a compartilhar cada vez mais as fadigas das personagens envolvidas na narração" (MASCILONGO, 2011, p. 175).

Nessa avaliação de conjunto, as mulheres têm vindo a assumir importância na exegese, como objeto de estudo. Trata-se de personagens secundárias no tempo de Jesus por toda a envolvência cultural e de personagens terciárias narratologicamente. Todavia, essa penumbra não escamoteia a sua importância catecumenal e narrativa. Com efeito, a essas personagens tritagonistas (cf. Mt 9,20; 15,22; 26,7; 28,5; Mc 5,25; 7,25; 14,3; Lc 7,37-50; 8,2.43; 10,38; 13,12; 23,27.49.55), Marcos aplica o verbo akolouthéo (seguir), o verbo do seguimento catecumenal, que em Marcos não é mimético (KOWALSKI, 2019, p. 600). Elas seguem Jesus desde a Galileia (Mc 15,4041) e elas servem Jesus. Elas têm uma theōría primeiro no sepultamento de Jesus (v. 47) e depois na ressurreição $(16,4)$, ou seja, uma experiência mistagógica própria dos catecúmenos (KOWALSKI, 2019, p. 601). Essa experiência não termina aí. Essa experiência é intensificada com o verbo da identificação, o eîdon do jovem que elas veem vestido de branco no sepulcro em 16,5. Todavia, esse catecumenato será ainda mais intenso, com uma experiência importante depois da ressurreição que é o encontro na Galileia. Aí, elas e os discípulos o voltarão a encontrar: "lá o vereis" (v. 7). Essa experiência é "expressa com um outro verbo, com ópsomai, que em Marcos é usado para observações muito especiais que têm por objeto o Filho do Homem" (IERSEL, 2000, p. 447).

\section{Os começos do catecumenato no evangelho de Marcos}

Em Marcos, Jesus inicia a sua grande catequese até Jerusalém, começando por anunciar na Galileia, onde os discípulos adultos vivem que "cumpriuse o tempo e está próximo o reino de Deus; convertei-vos e acreditai no evangelho" $(1,15)$. Esse processo de maturação da fé dos discípulos - homens adultos que formam um grupo heterogêneo - começa não com a transmissão de um corpo doutrinal, mas com o anúncio da boa notícia de que o reino está entre eles, pelo fato de que eles fazem já parte do reino, já vivem no reino. Esse catecumenato começa com este anúncio, com uma pregação e não com resenhas doutrinais: o reino de Deus fez-se próximo em Jesus, familiarizou-se em Jesus, pelo que os catequizandos estão aproximados e incluídos no reino por Jesus, fazendo assim uma experiência pessoal e de encontro - sendo encontrados. Por isso, a conversão consiste em acreditar no evangelho (o que é dito com um kai explicativo: "convertei-vos, isto é, acreditai no evangelho"). Ora, tendo presente que Jesus é não 
só o anunciador do evangelho, mas também o seu conteúdo (Mc 1,1), converter-se significa então, em Marcos, acreditar em Jesus, tornar-se seu discípulo (1,16-20; 2,13-18). Assim, além do anúncio dessa boa notícia, esse catecumenato começa também com o anúncio da necessidade de conversão, o que, nos tempos que correm, poderia até ser considerado antipedagógico e pouco motivador (como ensinam as técnicas de coaching). Seja como for, a iniciação à fé desses discípulos adultos pressupõe alguma conversão, isto é, já alguma empatia na fé, ou seja, um coração disponível a receber a graça e a desenvolver aquela empatia inicial com o evangelho a que a teologia chamará a fé teologal.

Onde é que Jesus inicia esse catecumenato? Jesus chama os discípulos onde eles estão - a pescar na Galileia (cf. Mc 1,16-20). É aí que respondem ao convite em 1,20b, não em qualquer outra situação: "Deixando o seu pai Zebedeu no barco com os assalariados, partiram atrás dele". Esse catecumenato implica cedências, opções difíceis, e ir atrás de Jesus, segui-Lo. Esse catecumenato no evangelho começa por ser um seguimento atrás de Jesus. É assim que Jesus começa-os a mergulhar na sua vida. Jesus começa, assim, a batizá-los antes de os batizar no batismo da cruz, como anunciará aos filhos de Zebedeu (Mc 10,38). Para isso, precisa da liberdade desses adultos: esses discípulos adultos tiveram de se predispor a fazer escolhas, a percorrer esse catecumenato, indo atrás de Jesus.

Num dia típico em Cafarnaum (Mc 1,21-39), Jesus começa o seu catecumenato rezando logo ao alvorecer, muito cedo, "ainda escuro" (v. 35), de madrugada (vv. 35-38); em seguida, ensina logo de manhã na sinagoga (vv. 21-28); à hora do almoço surge na casa de Simão (vv. 29-31), e à tarde está diante da porta da casa de Simão Pedro (v. 32-34) a receber, a cuidar dos doentes e dos mais frágeis. Essa é a jornada típica de Jesus no evangelho de Marcos. Esse é o catecumenato diário do Nazareno, pois um catecumenato feito por Jesus pressupõe tempo, exige vários encontros ao longo do dia, durante o qual se vão construindo relações interpessoais e comunitárias. Trata-se, portanto, de uma experiência comunitária de familiarização no meio da vida quotidiana banal e comum. Só depois disso é que, em Mc 3,14, Jesus, após ter criado todas essas condições e essa experiência de comunidade, "constituiu Doze, aos quais também chamou apóstolos, para estarem com Ele". É nesse mergulho de vida que Jesus quer introduzir os discípulos. Esse será o mote de todo o evangelho: narrar como Jesus vai fazer para estarem com Ele (PALACHUVATTIL, 2010, p. 159) - esse é o objetivo do catecumenato. Ora, para alguém estar com alguém precisa de tempo, de vários tempos, até de muito tempo, para se irem encontrando, conhecendo e conversando. Se Jesus quer que eles estejam com Ele, tem de criar as condições para tal, tem de dar tempo de encontro aos discípulos. Isso acontece num processo de familiarização, de criação de condições e de relações familiares, de proximidade, de conhecimento, de empatia, pois ninguém ama aquilo que não conhece. 
Em Marcos, Jesus anuncia o evangelho do Filho de Deus, o servo. É assim que Ele é apresentado pelo evangelista logo no título do evangelho em 1,1. Depois anuncia o evangelho do reino através daquilo a que o Papa chama uma "intimidade itinerante" (FRANCISCO, 2013, n. 23). Então, em Marcos, a boa notícia de Jesus é a de que Ele quer que os discípulos estejam com Ele, partilhem a sua vida, aprendam no contato quotidiano e familiar. É assim que a Igreja é constituída no segundo evangelho canônico. Em Marcos, a Igreja nasce na missão discipular iniciada por Jesus na Galileia, e a comunidade dos discípulos existe para "estarem com Ele" $(3,14)$, para ser verdadeiramente discípula, para seguir Jesus até à cruz, para o seguir nos caminhos da vida, mesmo nos momentos mais difíceis como será o do processo da paixão e morte. A missão marcana da Igreja é a de ser discípula de Jesus, de se pôr à escuta de Jesus, de $\mathrm{O}$ seguir, de ir atrás d'Ele, de mais nada e de mais ninguém, só de Jesus, o único Ungido de Deus. A boa notícia é a de que Jesus quer estar com os discípulos, quer estar com eles e quer desde o início que eles permaneçam consigo, que estejam com Ele. A boa notícia de Jesus consiste no seu desejo-missão de criar comunhão de vida com os discípulos, de querer viver com eles, de os ter por perto, de partilhar o quotidiano com eles, de lhes abrir o coração e as Escrituras, de os introduzir ao sentido da sua vida de entrega pelo mundo. Ora, Jesus sabe que isso não pode ser feito de um dia para o outro: exige tempo, dedicação, paciência, pedagogia, suportação, condescendência, como é normal nos processos de crescimento, ainda mais quando é feito com adultos como é o caso dos discípulos, os quais trazem consigo muitos preconceitos, ideias pré-concebidas, desejos infundados, expetativas goradas, vícios, desconfiança até.

\subsection{Os processos}

Como era feito esse catecumenato? Em Mc 4,2, Jesus "ensinava muitas coisas em parábolas", isto é, com pedagogia, com criatividade, e não com fórmulas abstratas. Essas estão compendiadas no edifício doutrinal da Igreja e estavam na lei de Moisés como também na tradição oral da torah shê bê-alpê. Sobretudo essa última era muito conhecida e praticada pelos fariseus, que tinham com o Deus de Israel uma relação formal baseada em fórmulas e princípios abstratos, hipostasiando Deus na letra da lei (Mt 23,23-29; Mc 2,24; 7,3; 12,15; Jo 7,19.51; 12,34; 19,7).

Para desenvolver o catecumenato com os seus ${ }^{4}$ discípulos, Jesus sobe ao monte e constitui os Doze, cria um pequeno grupo próximo (a sua verdadeira família) que se distingue dos que "estão fora" (Mc 3,31; 4,11). À multidão anuncia o reino em parábolas $(4,1-34)$, mas reserva a explicação

${ }^{4}$ Esse pronome é repetido à saciedade por Marcos, sendo muitas das vezes desnecessário. Trata-se de um semitismo do evangelho. 
para o grupo dos mais próximos, a eles "explicava tudo em privado" $(4,34)$. O processo de iniciação pressupõe tempo para esse ensinamento personalizado, que só consegue ser feito em pequeno grupo, pois necessita de tempo, de atenção e de escuta por parte de quem explica, que por sua vez precisa de dar tempo a quem pergunta e quer conhecer. Jesus mostra que não é possível conhecer alguém em catecumenatos massificados, no anonimato da multidão. Para chegar a acreditar que Ele é o Filho de Deus, terão de percorrer com Ele o percurso até à cruz. Mas esse percurso tem de ser acompanhado, tem de ser apoiado. Isso não consegue ser feito no meio ou com uma turba. A pedagogia do pequeno grupo é adotada por Jesus. Jesus instaura com os discípulos uma relação personalizada, dirigida. Isso lhe permite tempo para contar histórias adaptadas ao seu grupo. Assim se compreende que lhes fale em parábolas.

Além desta originalidade de Jesus de ensinar com e através de histórias parabólicas, em Mc 14,32, na Paixão, Jesus desafia também os discípulos a orar: "sentai-vos aqui enquanto vou rezar." Jesus introduz no mundo da oração e da intimidade com o Pai, introduz a uma autêntica experiência espiritual. Esse batismo de oração (esse mergulho) não acontece apenas na Paixão, mas também ao longo do ministério galilaico, pois já antes durante o seu ministério público, Jesus retira-se várias vezes para rezar, e já tinha levado Pedro, Tiago e João com Ele para estarem com Ele no alto do monte na Transfiguração em Mc 9,2-9. Nesse processo de crescimento, Jesus introduz os discípulos a uma intimidade itinerante consigo e com o Pai (PALACHUVATTIL, 2010, p. 155), levando-os pessoal e privadamente consigo, kat'idian mónous.

Onde é que isso é feito? "No caminho" (en te $\bar{i}_{i}$ hodō $_{i}$ ), isto é, na partilha diária da vida (LENTZEN-DEIS, 1997, p. 237), no quotidiano, na proximidade, no contato pessoal. Isso mostra que também faz parte do processo de catecumenato a oração, a companhia e a liturgia. Ambas fazem parte da vida, não são setores estanques, pelo que Jesus não separa a oração da vida e da história:

para não separar a moral da ética, por não separar a ética do rito, por não separar o rito da liturgia nem a liturgia da vida (que desemboca naquilo a que hoje se chama a privatização do religioso, expressão cultural do individualismo atual exacerbado), Jesus foi contestado (CARVALHO, 2011, p. 245).

Isto mostra que Jesus foi um verdadeiro acompanhante espiritual desses discípulos adultos. Desse processo de crescimento, dessa iniciação à fé, faz parte a vida orante, a experiência espiritual de rezar. Por isso, quando não se tem em conta todos esses dados fundamentais, Jesus é transformado em muitas figuras, como no

Jesus moralista ou guru de ética de Thomas Jefferson e de muita modernidade; ou no Jesus conselheiro psicológico a sugerir coisas hipotéticas, calorosas e confusas; ou num Jesus crítico social e ativista político a sugerir vias de ação 
ou de intervenção social; ou até mesmo num Jesus permissivo, individualista, amorfo, quase que indiferente, porque tolerante ao ponto de tudo tolerar com base numa atitude amorosa romântica e pacifista (tão a gosto dos nossos contemporâneos), mas sem qualquer relevância pública e social (CARVALHO, 2011, p. 244-245).

Não é por essas vias que Jesus quer conduzir os discípulos, nem para isso que Jesus quer que eles estejam com Ele. Assim se compreende que os fariseus estivessem muito distantes da verdadeira vida, pois estavam iniciados noutras tradições, noutros vícios. Tinham sido mergulhados nas bizantinices da tradição oral que não tinham importância perante o que é fundamental: a relação pessoal com o Deus de Israel. Isso mesmo é relatado por Marcos a propósito do embate de Jesus com os fariseus ao longo do seu ministério, como por exemplo ainda na Galileia:

${ }^{1}$ Reuniram-se junto dele os fariseus e alguns dos doutores da lei vindos de Jerusalém. ${ }^{2}$ Ao verem que alguns dos seus discípulos comiam os pães com mãos impuras, isto é, sem as lavar (aniptois), ${ }^{3} \mathrm{de}$ fato, os fariseus e todos os judeus não comem sem terem lavado (nípsōntai) as mãos até ao punho, agarrados à tradição dos antigos, ${ }^{4} \mathrm{e}$, ao voltar da praça pública, não comem sem se terem lavado (baptísōntai); e agarram-se por tradição a muitas outras coisas, como a lavagem (baptismoús) de copos, vasos, utensílios de cobre e camas (Mc 7,1-4).

O verbo grego traduzido por lavar é baptízō, e o substantivo lavagem é baptismós; trata-se de uma ironia: os fariseus não recebem o batismo de conversão nem o do Espírito, mas batizam-se para comer, batizam os utensílios e até o próprio leito. Ou seja, ficam-se pelo aspecto, pelo exterior, pelas aparências, pois reduzem o batismo a um rito. Para os fariseus não é um processo, deixou de ser a iniciação e a comunhão com a vida. Já no tempo de Jesus muitos reduziam assim o batismo ou a um ato ritual ou a preocupações estéticas secundárias. Sendo o batismo uma iniciação, traduzido ritualmente por um banho iniciático, os fariseus mostram que se iniciaram no que não é fundamental, tendo absolutizado o que é secundário, o que mostra que a iniciação batismal catecumenal pode perder o seu norte e o seu significado.

Desde o início da subida para Jerusalém, em Mc 8,27, é que Jesus interrogava os seus discípulos. De fato, nessa subida para Jerusalém - que é um esforço por parte de Jesus para que os discípulos ascendam e cresçam teológica e espiritualmente - Jesus usa o método maiêutico, colocando questões, obrigando os discípulos a dizerem-se, a buscar o sentido dos acontecimentos e das coisas. Jesus interroga para auscultar as motivações profundas dos seus ouvintes mais diretos, como é próprio de um processo de acompanhamento espiritual intrínseco ao crescimento na fé cristã.

\subsection{O seguimento do discipulado}

A temática do discipulado atravessa assim todo o evangelho de Marcos. Parece que Jesus não sabe viver sem os discípulos, pois esses acompanham- 
No permanentemente. Essa união começa nos primórdios do ministério na Galileia, desde a primeira jornada em Cafarnaum. Ao contrário, Lucas constrói uma progressão entre a atividade de Jesus (evangelizador solitário) e o chamamento dos primeiros discípulos. Em Lucas há um espaço. A companhia não é tão contínua nem tão patente como em Marcos.

O discípulo é implicado no caminho do mestre. Jesus é sempre Aquele que chama, que precede os discípulos. Em consequência, o verbo que qualifica o estado e a missão do discípulo é akolouthéo (seguir). O discípulo é o que anda atrás do Mestre e, metaforicamente, partilha o modo de vida e a experiência do Mestre. No início do evangelho encontramos quatro homens que se confiam a Jesus (1,16-20): Simão e o seu irmão André, e Tiago e o seu irmão João (ambos filhos de Zebedeu). Seguem o caminho de Jesus, mostrando assim que o tempo da verdade do reino chegou. Também as mulheres são definidas com o mesmo verbo. Mas esses são apenas os inícios cor-de-rosa. As dificuldades virão a seguir quando Jesus começar a apresentar as exigências do reino e de seguir atrás dele. Não admira que os primeiros chamados deixem tudo "imediatamente" $(1,18.20)$. Os problemas virão a seguir, e serão de tal ordem que os farão abandonar Jesus. Ou seja, os discípulos começaram esse catecumenato, mas não o acabaram: não vão levar esse processo até ao fim, pois vão abandoná-Lo. Esse catecumenato está marcado pela "incompréhension qui caractérise le mieux les faiblesses des disciples" (BAUDOZ, 2009, p. 38).

Como vê então Marcos os discípulos e os Doze? Se Marcos olha para o catequista Jesus, agora olhamos também com Marcos para os catequizandos - os discípulos - que, significativamente, são chamados sempre de "discípulos" com a palavra grega "mathētēs", que quer dizer aprendizes. Os discípulos seguem Jesus, mas não $O$ entendem. Marcos não atenua o papel dos discípulos nem as dificuldades que tiveram nesse processo de iniciação à fé. Não atenua a sua dureza de coração. No fim, Jesus é abandonado por todos $(14,50)$. Todos fogem. Só as mulheres aguentam até ao Calvário (15,40-41). Paradoxalmente, os discípulos, os iniciados, nunca são apresentados como modelos de fé, antes como exemplos de incredulidade (9,14-29), e isso de propósito em vista do narratário e do leitor extradiegético. Apesar disso, Marcos insiste em apresentar o esforço de Jesus com os seus discípulos. Jesus não abandona os seus educandos. Não os abandona à sua cegueira, mas leva-os pacientemente ao reconhecimento do seu mistério. Em privado, explica-lhes os seus ensinamentos em parábolas. Partilha com eles a vida e a responsabilidade da missão. Jesus estabelece com os discípulos relações de profunda amizade, de comunhão de vida. A última palavra confiada às mulheres por parte do jovem vestido de branco é sintomática e dirigida especificamente aos discípulos em 16,7 ("parti e dizei aos seus discípulos e a Pedro que Ele vos precede na Galileia; aí O vereis tal como vo-lo disse"). De fato, o Ressuscitado espera-os e precede-os, não no monte das Oliveiras onde foi abandonado 
por eles, mas na Galileia onde os encontrou e onde ficaram estagnados neste longo processo catecumenal. Por outras palavras, Jesus começa tudo de novo depois da ressurreição, de forma positiva, dá-lhes a possibilidade de um recomeço, de uma nova hipótese. Jesus volta a estabelecer com os discípulos a relação de confiança destruída no coração deles. Jesus volta a basear a relação do crer na relação do "ver" (cf. Mc 8,22-25; 10,46-52; 14,61-62; 15,29-39; 16,1-7). E vai buscá-los onde os encontrou e de onde eles nunca saíram nem teológica nem espiritualmente: ficaram estagnados na Galileia, lá longe de Jerusalém, geográfica e teologicamente distante, mesmo tendo em conta que em Marcos a Galileia nunca é apresentada como a Galileia dos gentios. Isso significa que os discípulos, na prática, não fizeram um percurso catecumenal com Jesus até Jerusalém: subiram apenas geograficamente, mas não teológica nem espiritualmente. Esses catecúmenos padecem de uma "falta de perspicácia espiritual" (LÉGASSE, 1997, p. 59, tradução nossa). Ficaram atolados longe daquela Jerusalém na qual Jesus queria que eles entrassem com Ele. Com efeito, na construção marcana do evangelho, e no que ao discipulado diz respeito, "a fragilidade dos discípulos é uma das características da narrativa de Marcos" (BOURQUIN, 2019, p. 71, tradução nossa).

\subsection{O caminho catecumenal dos discípulos}

Antes de os enviar dois a dois, Jesus chama-os a si (o mesmo verbo de $3,13)$, os Doze, quase para forçar essa relação com Ele. A parte central de Mc 6,6b-8,21.(22-26) está dominada pela revelação de Jesus em duas grandes cenas paralelas da multiplicação dos pães (cf. 6,30-44; 8,1-9). Com isto os discípulos deveriam compreender a identidade messiânica de Jesus, mas mesmo assim não o entendem. A cura do cego de Betsaida de 8,2226 mostra que só Jesus pode curar a cegueira humana. Essa seção central desenrola-se toda no caminho. Essa expressão forma uma grande inclusão com Mc 10,52 onde surge novamente a balizar toda essa seção a cura de um outro cego (em Jericó). Ambas indicam respectivamente o extremo norte e o extremo sul do caminho de Jesus. Esse caminho catecumenal de iniciação à vida da fé realiza-se em três seções geográficas distintas: a zona de Cesareia de Filipe $(8,27)$, na Galileia $(9,30-50)$ e na Judeia além Jordão (10,1-52). O elemento que unifica a apresentação de toda essa seção não é uma localização de fundo comum. Jesus não está sempre no mesmo lugar ao longo desses capítulos. O que unifica é precisamente a referência repetida ao caminho. É aí que Jesus está e é aí que coloca os discípulos (MANICARDI, 1981, p. 99). Desse modo, Marcos constrói precisamente um catecumenato como ele é - uma caminhada não geográfica, mas teológica: "este caminho de Jesus não tem apenas um significado cênico-geográfico, mas também uma dimensão teológico-cristológica" (SCHENKE, 2005, p. 197, tradução nossa). Trata-se, portanto, de um processo em que vão sendo construídas relações de familiaridade. 
Essa subida para Jerusalém é atribulada no sentido em que não é edênica, não é sempre ascensional. Pedro sente até o dever de intervir chegando mesmo a repreender Jesus em 8,32. Mas Jesus repreende o discípulo com o mesmo verbo (" $[. .$.$] ordenou a Pedro e disse-lhe: 'parte para trás de Mim,$ satanás, porque não pensas as coisas de Deus, mas as dos homens'") e ordena-lhe para se colocar "atrás" de Si, não longe, mas no seu seguimento. Pedro, o catequizando, um dos aprendizes, um dos iniciados, quer ser ele a comandar o caminho, a liderar o grupo, até a dar ordens a Jesus e a dizer-Lhe o que Ele deve fazer. Esse catequizando insubordinado quer perverter os lugares e as funções dentro do grupo, arroga-se mais do que aquilo que sabe e do que pode dar.

Ora, sendo essa iniciação um caminho - ou seja, uma caminhada - isso implica um esforço de reflexão e de empenho pessoal quer no conhecimento desse caminho quer no compromisso que daí decorre. Como qualquer processo, nem sempre é linear. Recorre a vários meios, que podem não conseguir conduzir ao objetivo desejado, visto que a liberdade humana continua a ser um mistério.

O percurso dos discípulos no evangelho de Marcos mostra que os processos catecumenais são fundamentais, pelo que, nesse evangelho, o batismo começa antes do batismo, começa nos praenotanda. Se por um lado começa antes, narrativamente também começa depois da ressurreição. Com efeito, a missão é anterior e posterior à celebração. Ela é prévia como construção da familiaridade, e é posterior na medida em que é missionária, ou seja, convocada à partilha do dom da salvação. Assim, o discípulo catecúmeno e o leitor ouvinte têm de continuar a reencontrar o Ressuscitado nos caminhos da história depois daquele medo com que termina a narrativa evangélica na primeira conclusão em 16,8. O anúncio do reencontro com o Ressuscitado na Galileia (ópsomai: v. 7) não é um convite a uma experiência meramente mística para o leitor ouvinte. Assim, "Jesus, agora que está ressuscitado e que o lugar da sua sepultura não tem qualquer importância, caminhará à frente onde quer que algum discípulo esteja disposto a segui-Lo" (IERSEL, 2000, p. 459).

\subsection{O fundo paulino do catecumenato marcano}

Marcos é aquele que escreve mais próximo no tempo de Paulo, e partilha com ele a preocupação por apresentar Jesus como o grande catequista e, assim, a iniciar e reiniciar constantemente processos. No caso do Apóstolo das Gentes, quando escreve à sua amada comunidade de Corinto durante a terceira viagem missionária (cf. At 18,23-21,16), Paulo pretende corrigir um processo catecumenal, entretanto, já iniciado (PESCE, 1994, p. 12.32), tal como Jesus já tinha feito com os seus discípulos adultos a partir da Galileia. No epistolário protopaulino, encontramos, assim, a segunda fase da evangelização. As cartas ecoam um trabalho de evangelização 
já iniciado (PESCE, 1994, p. 10). Aos adultos da capital da província da Acaia, Paulo indica, sem exortar, a origem da respetiva identidade da cruz do Senhor Jesus, do próprio Deus, e as consequências dessa ação para a vida da comunidade. Se a comunidade está dividida - tal como acabaram os catecúmenos discípulos em Marcos - isso significa que não compreenderam bem nem o que significa a loucura da cruz nem o Crucificado. É para aqui que Paulo quer levar a comunidade, como é para aqui que Jesus quer levar os seus aprendizes - a compreender que a cruz é o grande batismo. Jesus quer levar os seus catecúmenos até à cruz, até Jerusalém: também Paulo quer levar os seus irmãos de Corinto, já iniciados na fé, ao encontro da loucura da cruz. Por isso, Paulo corrige. Mas trata-se de uma correção teo-lógica, e não soteriológica, no caso de 1Cor. Tal como o catecumenato dos discípulos em Marcos, esse é também um catecumenato teo-lógico no sentido em que educa para o conhecimento da lógica paradoxal da ação de Deus É essa lógica da reflexão paulina que Marcos apresenta como incompreendida pelos discípulos. Marcos retrata as dificuldades do catecumenato dos discípulos de Jesus. Paulo reencontrará também dificuldades em Corinto com os seus irmãos recém-chegados à fé. Perante isso, Paulo ausculta epistolarmente a comunidade, tentando mostrar-lhe o paradoxo da cruz, a inversão da lógica humana por parte de Deus. Essa lógica também não tinha sido compreendida pelos discípulos durante o ministério público de Jesus. Há, todavia, que salientar que a argumentação paulina é discursiva (na primeira parte de 1Cor), enquanto a marcana é narrativa. Mas isso não impede uma aproximação temática ao objetivo do catecumenato comum proposto aos discípulos e à comunidade de Corinto.

A correção argumentativa teo-lógica de Paulo à comunidade da península da Acaia é descrita com as técnicas retóricas da expolitio e da correctio, e com os tropoi da metonímia e da ironia, entre outros (GIORDANO, 2010, p. 140.154.182), dispositivos ausentes em Marcos. Na seção epidítica de 1Cor 1-4 (SMIT, 2003, p. 189) com que 1Cor começa, depois do exordium de 1Cor 1,10-17, Paulo apresenta a propositio dessa seção no v. 18: “Com efeito, a palavra da cruz (lógos toû stauroû $)^{5}$ é loucura $(m o \overline{r i ́} a)^{6}$ para os que estão perdidos, mas, para os que estão salvos, para nós, é poder (dýnamis) ${ }^{7}$ de Deus." Tal como os discípulos em Marcos, também os irmãos na fé em Corinto ficaram aquém da lógica de Deus perante esse paradoxo (SMIT, 2003, p. 191). Afinal, os problemas do catecumenato mantiveram-se com o

\footnotetext{
${ }^{5}$ Até 2,5 a argumentação é teo-cristológica sobre o redimensionamento dos valores operado pela cruz, que Paulo vai concretizando progressivamente; a fórmula a palavra da cruz é solene e não existe outra igual em todo o NT.

${ }^{6}$ Epíteto paradoxal sobre a palavra da cruz (cf. Is 52,13-53,12; Jo 3,14; 8,28; 12,32.34; 19,37; Zc 12,10; Nm 21,4-9).

${ }^{7}$ Os vv. 19ss são considerados uma espécie de sub-propositio (sub-tese) que Paulo aprofunda até ao fim do cap. 4.
} 
Jesus da história e com o Cristo da fé, ou seja, quer durante o ministério público de Jesus narrado por Marcos, quer alguns anos após Paulo ter encontrado dificuldades semelhantes numa das suas comunidades. Por isso, desse catecumenato fará parte a catequese sobre o kerygma; vai ser necessário continuar a anunciar e a comentar: "proclamamos Cristo crucificado, escândalo para os judeus e loucura para os gentios." (1Cor 1,23). Os catecúmenos discípulos aprendizes em Marcos também não queriam esse Messias Crucificado.

Perante isso, Paulo mostra, indica as componentes da sabedoria (cf. 1Cor 1,19-2,5): pode ser um conceito ambíguo; a sabedoria humana opõe-se à sabedoria divina; é um paradoxo um messias Crucificado (cf. 2 Cor 5,21; 8,4; Gal 3,13; Rom 3,23-25; 8,3-4); e a sabedoria de Deus é totalmente diversa da humanidade, pois a sua especificidade reside na debilidade como meio de demonstração (GIORDANO, 2010, p. 213-223). Desse modo, na retórica de 1Cor 1,20b ("não enlouqueceu Deus a sabedoria do mundo?") o verbo "mōraíno" reenvia:

ao núcleo do anúncio, ao evento histórico da crucifixão de Cristo como manifestação insensata através da qual o desígnio de Deus quis chegar à humanidade [...] a 'mōría' é uma concentração polissêmica, um ponto nodal de ambivalência que serve a Paulo para descrever a reviravolta dos valores operada por Deus através da palavra da cruz (GIORDANO, 2010, p. 102).

Sem ser narrativa como é a exposição marcana, a argumentação paulina explora o próprio paradoxo da cruz. Com os vários dispositivos retóricos, o Apóstolo das Gentes apresenta o conteúdo num estilo paradoxal, ou seja, o estilo paradoxal já é a mensagem. Esse paradoxo é muito mais explicado por Jesus ao longo da subida catecumenal para Jerusalém. Em ambiente familiar, o Jesus de Marcos reúne os seus e explica-lhes em privado, por três vezes, as consequências e os objetivos desse processo catecumenal. Também Paulo tenta reinstaurar um processo catecumenal em Corinto. Para ambos os escritos sagrados, os objetivos e as consequências são os mesmos. A maneira de apresentá-los por escrito é que tem variações.

\section{Conclusão}

Nem Paulo em 1Cor 1-4, nem Marcos, abordam a dimensão ritual do batismo. Num contexto kerigmático, de pregação, o mais importante é iniciar processos, nesse caso, um processo catecumenal. A envolvência familiar desse processo é bem mais patente em Marcos do que na primeira parte de 1Cor. Sem ser esse o objetivo desta reflexão, encontramos algumas pistas com incidência pastoral, sobretudo no lugar a dar aos praenotanda, parágrafos tão importantes na preparação e para o sucesso 
de autênticos percursos catecumenais, e que aqui quisemos ver na sua impressão bíblica. Com efeito, hoje, a complexidade da evangelização, nesse contexto generalizado de indiferença e de neognosticismo (FRANCISCO, 2018, n. 37-46), consiste na dificuldade de encontrar e de construir percursos de fé, lugares e tempos de crescimento da e na fé, autênticos roteiros catecumenais, com as exigências que decorrem dessa autenticidade. $\mathrm{O}$ evangelho de Marcos é iluminador nesse sentido, pelo estilo de Jesus, pela sua postura, pelo seu empenho e cuidado personalizado. Paulo percebeu isso, sentindo a necessidade de agregar colaboradore(a)s para uma tarefa tão ingente. Jesus faz isso sozinho em Marcos, pois Ele é o Mestre, no caso de Marcos, é o servo. Esta condição do quarto canto do servo de Javé (cf. Is 52,13-53,12) revoluciona por completo as expectativas dos discípulos, pois não estavam à espera de serem orientados (catequizados) por um servo assim (MAZZUCCO, 1999, p. 99). Todavia, a exegese tem mostrado que, apesar de tudo, esses catecúmenos vão tendo momentos de aproximação ao mistério do seu Senhor (SCHENKE, 2005, p. 207). De fato, Jesus não nega a resposta de Pedro na confissão de Cesareia (Mc 8,29), mesmo que seja uma "partial sight" (LANE, 1974, p. 287), mas contesta a reação seguinte. A ambiguidade da resposta petrina não fecha o catecumenato. Por não fechar, permite que prossiga até Jerusalém. No fim, Jesus devolve os seus discípulos catecúmenos ao mundo. $\mathrm{O}$ mundo na primeira conclusão do evangelho é a Galileia (CUIVILLIER, 2002, p. 9.16.310), pois esse mundo é o tempo da missão. Assim tem a exegese marcana vindo a superar a famosa tese do conflito entre Jesus e os discípulos (KINGSBURY, 1991, p. 24-26). A Galileia é o início. O fim do evangelho não é o fim, mas um início. A Galileia abre o catecumenato ao mundo (PIKAZA, 1996, p. 423.432; NAVARRO PUERTO, 2006, p. 582).

Apesar do esforço de familiarização desenvolvido por Jesus, Marcos mostra como algumas personagens não principais estão mais abertas a iniciar esses processos catecumenais do que os próprios discípulos, supostamente mais próximos e íntimos de Jesus. Ora, também essas são categorias relacionais nos evangelhos e que, por isso mesmo, espelham a possível ambiguidade desses processos. Assim se compreende que a anagnorese no evangelho de Marcos vai tendo vários momentos - como qualquer processo catecumenal, é marcada por várias etapas. Narrativamente, isso é narrado em Marcos pelo protagonista Jesus e pelas personagens deuteragonistas e tritagonistas. Essas personagens permitem uma diegese interna e externa, pois "servem a Jesus como os discípulos deveriam fazer, mas não fazem" (KINGSBURY, 1991, p. 47). O leitor ouvinte vê-se envolvido nesses níveis de narração e reencontra a sua Galileia, vê-se espelhado na sua Galileia, isto é, no seu mundo (LENTZEN-DEIS, 1997, p. 429; CAMACHO; MATEOS, 1994, p. 283). É aí que os catecúmenos constroem o reino. 


\section{Siglas}

NT $=$ Novo Testamento

RICA = Ritual de Iniciação Cristã de Adultos

\section{Referências}

ALETTI, J. N. I personaggi e i lettori di Mc Orientamenti metodologici nuovi. In: I Vangeli Sinottici: Matteo e Marco Seminario per gli studiosi di Sacra Scrittura Roma 26-30 gennaio 2015: e-biblicum. Roma: G\&B Press, 2015. p. 21-33.

ALETTI, J. N. (Et al.). Vocabulario razonado de la Exégesis Bíblica: los términos, las aproximaciones, los autores. Navarra: Verbo Divino, 2007.

ALETTI, J. N. La construction du personnage Jésus dans les récits évangéliques. Le cas de Mc. In: FOCANT, C.; WÉNIN, A. (Ed.). Analyse narrative et Bible. Deuxième colloque international du RRENAB. Louvain-la-Neuve - avril 2004: Bibliotheca Ephemeridum Theologicarum Louvaniensium. Leuven: Peeters, 2005. v. 191, p. 19-42.

ARANDA GARRIDO, P. La casa, espacio de memoria e identidad en el Evangelio de Marcos. Madrid: Universidad Pontificia, 2009.

BAUDOZ, J. F. Prendre sa croix. Jésus et ses disciples dans l'évangile de Marc, lire la Bible. Paris: Cerf, 2009. v. 154.

BOURQUIN, Y. La troisième dimension de l'intrigue chez Marc. In: PASQUIER, A.; MARGUERAT, D.; WÉNIN, A. (Eds.). L'intrigue dans le récit biblique: quatrième colloque international du RRENAB. Louvain-la-Neuve - avril 2004: Bibliotheca Ephemeridum Theologicarum Louvaniensium. Leuven: Peeters, 2010. v. 237, p. 25-36.

BOURQUIN, Y. La Passion chez Marc: Théologie de la fragilité - fragilité de la théologie? Marc 14-16: le silence du ciel et les silences du récit. In: VAN OYEN, G. (Ed). Reading the Gospel of Mark in the twenty-first century Method and Meaning: Bibliotheca Ephemeridum Theologicarum Louvaniensium. Leuven: Peeters, 2019. v. 301, p. 69-86.

BREYTENBACH, C. Das Evangelium nach Markus: Verschlüsselte Performanz? In: VAN OYEN, G. (Ed). Reading the Gospel of Mark in the twenty-first century Method and Meaning: Bibliotheca Ephemeridum Theologicarum Louvaniensium. Leuven: Peeters, 2019. v. 301, p. 87-114.

BROWN, R. E. The Death of the Messiah. From Gethsemane to the Grave. A Commentary on the Passion Narratives in the Four Gospels. New York 1994. v. 2.

CAMACHO, F.; MATEOS, J. Marcos: texto y comentario. Córdoba: El ALmendro, D.L., 1994.

CARVALHO, J. C. O Jesus da história entre a lei e o amor". Didaskália, Lisboa, v. 41, n. 1, p. 235-255, 2011.

CARvalho, J. O. Caminho de morte destino de vida: o projecto do Filho do Homem e dos seus discípulos à luz de Mc 8,27-9,1: Fundamenta. Lisboa: Didaskalia, 1998. v. 18.

CUVILliER, É. L'Évangile de Marc. Paris: Bayard, 2002. 
FOCANT, C. Marc, un évangile étonnant: recueil d'essais: Bibliotheca Ephemeridum Theologicarum Louvaniensium. Leuven: Peeters, 2006. v. 194.

FOCANT, C. Le rôle des personnages secondaires en Marc: l'exemple des récits de guérison et d'exorcisme. In: STEFFECK, E. - BOUQUIN, Y. (Éds.). Raconter, interpréter, annoncer. Parcours de Nouveau Testament. Mélanges offerts à Daniel Marguerat pour son 60e anniversaire: Le Monde de la Bible. Genève: Labor et Fides, 2003. v. 47, p. $115-126$.

FOCANT, C. L'incompreension des disciples dans le deuxième évangile. Revue Biblique, Leuven, v. 82, n. 2, p. 161-185, Abr/June. 1975.

FRANCISCO, Papa, Exortação Apostólica Gaudete et Exultate, Vaticano, 2018. Disponível em: http://www.vatican.va/content/francesco/pt/apost_exhortations/documents/ papa-francesco_. Acesso em: 14 março. 2021.

FRANCISCO, Papa, Exortação Apostólica Evangelii Gaudium, Vaticano, 2013. Disponível em: http:/www.vatican.va/content/francesco/pt/apost_exhortations/documents/ papa-francesco_. Acesso em: 22 março. 2021.

GIORDANO, M. T. La parola della croce: l'itinerario paradossale della sapienza divina in 1Cor 1,18-3,4: Tesi Gregoriana Serie Teologia. Roma: G\&B Press, 2010. v. 180.

GNILKA, J. El Evangelio segun San Marcos: Biblioteca de Estudios Bíblicos. Salamanca: Sígueme, 1986. v. 56.

GONZÁLEZ RUIZ, J. M. Evangelio según Marcos: introducción, traducción, comentario. Estella: Verbo Divino, 1988.

HATCH, E.; REDPAHT, H. A concordance to the Septuagint and the other Greek versions to the Old Testament including the apocryphal books. Michigan: Baker Books, 1998.

IERSEL, B. v. Marco la lettura e la risposta: un commento. Brescia: Queriniana, 2000.

KINGSBURY, J. D. Conflicto en Marcos. Jesús, autoridades, discípulos. Córdoba: Ediciones El Almendro, 1991.

KOWALSKI, B. Generosity, Courage and Faith of Women Following Jesus in the Gospel of Mark. In: VAN OYEN, G. (Ed). Reading the Gospel of Mark in the twenty-first century Method and Meaning. Bibliotheca Ephemeridum Theologicarum Louvaniensium. Leuven: Peeters, 2019. v. 301, p. 595-616.

LANE, W. L. The Gospel according to Mark: New International Commentary of the New Testament. Michigan: Eerdmans, 1974.

LÉGASSE, S. L'Évangile de Marc. Lectio Divina commentaires. Paris: Cerf, 1997. v. 5.

LENTZEN-DEIS, F. O Evangelho de São Marcos modelo de nova evangelização. Lisboa: Difusora Bíblica, 1997.

MANICARDI, E. Il cammino di Gesù nel vangelo di Marco. Schema narrativo e tema cristologico. Roma: PIB, 1981,

MASCILONGO, P. Ma voi, chi dite che io sia?: analisi narrativa dell'identità di Gesù e del cammino dei discepoli nel Vangelo secondo Marco, alla luce della "Confessione di Pietro" (Mc 8,27-30). Analecta Biblica. Roma: Gregorian \& Biblical Press, 2011. v. 192. 
MAZZUCO, C. Lettura del Vangelo di Marco. Torino: Silvio Zamorani, 1999.

NAVARRO PUERTO, M. Marcos: Guías de Lectura del Nuevo Testamento. Estella: Verbo Divino, 2006. v. 1.

PALACHUVATTIL, J. Discipleship in the Gospel of Mark. In: DE SANTO, L. (a cura di). Perché stessero con Lui: scritti in onore di Klemens Stock SJ, nel suo 75을 compleanno. Analecta Biblica. Roma: PIB, 2010. v. 180, p. 151-186.

PESCE, M. Le due fase della Predicazione di Paolo: dall'evangelizzazione alla guida della comunità: Studi Biblici. Bologna: Dehoniane, 1994. v. 22.

PIKAZA IBARRONDO, X. Il vangelo di Marco. Roma: Borla, 1996.

SCHENKE, L. Das Markusevangelium Literarische Eigenart: text und Kommentierung. Stuttgart: Kohlhammer, 2005.

SMIT, J. F. M. Epideictic Rhetoric in Paul's First Letter to the Corinthians 1-4. Biblica, Roma, v. 84, n. 2, p. 184-201, Abr/June. 2003.

VAN OYEN, G. Du secret messianique au mystère divin: le sens de la narratologie. In: VAN OYEN, G. (Ed). Reading the Gospel of Mark in the twenty-first century Method and Meaning: Bibliotheca Ephemeridum Theologicarum Louvaniensium. Leuven: Peeters, 2019. v. 301, p. 3-38.

Artigo submetido em 29.03.2021 e aprovado em 20.07.2021.

José Carlos Silva Carvalho é Doutor em Teologia Bíblica pela Faculdade de Teologia da Universidade Católica Portuguesa (UCP - 2007). Professor Auxiliar na Faculdade de Teologia da UCP-CRP e Membro investigador do Centro de Investigação em Teologia e Estudos da Religião (CITER - UCP). Orcid.org/0000-0002-6460-9179. E-mail: josecarlossilvacarvalho@ gmail.com

Endereço: Rua $\operatorname{Arq}^{\mathrm{o}}$ João Andersen, 73, 5ํㅜㄹ Habt 5.6

4250-242 Porto - Portugal 